Dr Preya Pillay

University of the

Witwatersrand, Johannesburg

School of Education:

Curriculum

Email: preya.pillay@wits.ac.za

\section{Dr Eben Swanepoel}

University of the Free State,

Bloemfontein

Faculty of Education

Psychology of Education

Email: swanepoeleh@ufs.ac.za

DOI: $h$ ttp://dx.doi. org/10.18820/2519593X/pie. v36i2.10

ISSN 0258-2236

e-ISSN 2519-593X

Perspectives in Education

2019 36(2): 119-131

(C) UVIUFS

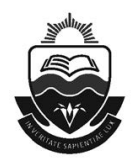

\section{An exploration of higher education teachers' experience of decolonising the Bachelor of Education honours curriculum at a South African university}

\begin{abstract}
The ongoing 2015/16 student unrest (\#RhodesMustFall; \#FeesMustFall) has displayed heightened calls for the decolonising of the curriculum in the higher education (HE) sector. Students have highlighted in the recent protests that the curriculum remains largely Eurocentric and continues to reinforce white and Western dominance. In response to the need for a decolonised curriculum, higher education lecturers at a university in South Africa embarked on a Bachelor of Education honours writing exercise workshop with the purpose of decolonising the curriculum. This entailed rethinking ways of knowing and a deconstruction of old epistemologies, with the aim that transformation in the classroom would be reflected in what is taught and how it is taught, as a means to ripple through to grassroots classroom level. This study explores, through using Foucauldian discourse as theoretical frame, the experiences of eight lecturers at a university involved in teacher induction of honours-level education students. This link serves as a fundamental basis between societal change that speaks to creating a space for the African child in challenging teacher conceptions of power and privilege and rethinking the norms of praxis that manifest when teachers enter the classroom. Semi-structured interviews were transcribed and thematically analysed to gain understanding as to the prominent methods used and the dominant conceptualisation of what decolonising the curriculum entails. Findings suggest a need to return to grassroots classroom level as a means to involve stakeholders, such as teachers and tertiary students, in shaping the curriculum. It is further found that lecturers lack the means to engage with a solely Afrocentric theoretical basis and that Western discourse remains a prominent source of knowledge due to the lack of indigenous knowledge systems and research.
\end{abstract}

Keywords: Decolonisation; higher education; curriculum reform; Foucauldian discourse; teacher induction; indigenous knowledge

\section{Introduction}

After 1994, transformation of knowledge was supposed to entail a "reorientation away from the [colonial and] apartheid knowledge system, in which curriculum was used as a tool of exclusion, to a democratic curriculum that is inclusive of all human thought" (Department of Education, 2008: 89). 
However, universities have been challenged in addressing the quality and overall transformation of the curriculum since the demise of apartheid (Akoojee \& Nkomo, 2007; Heleta, 2016). According to the Department of Education, in 2008 the transformational efforts have not "translated into any significant shifts in the structure and content of the curriculum" (Heleta, 2016:4). The curriculum is "inextricably intertwined with the institutional culture and, given that the latter remains white and Eurocentric at the historically white institutions, the institutional environment is not conducive to curriculum reform" (Heleta, 2016). This is in effect representative of the link between teacher induction and ultimately teacher praxis, as South Africa's sociocultural context is still facing post-apartheid based repercussions. In this the inequalities of service delivery and resource distribution are often scant within communities in which African learners are continuously facing the need and expected standard to abide with educators taught within a Western discourse (Theron \& Theron, 2014).

Garuba (2015) argues that to understand students' call for curriculum reform, we need to talk about and engage in the re-conceptualisation and decolonisation of the curriculum in South Africa. We need to consider the two approaches discussed by Garuba. The first approach is to "add new items to an existing curriculum". The second approach is to "rethink how the object of study itself is constituted" and then reconstruct it and bring about fundamental change (Garuba, 2015: 2). The emphasis is a critical account of knowledge production with the aim of valuing and including marginalised groups in the curriculum. This is similar to Ngugi's (1981: 87) argument, which states that decolonisation of the curriculum is about Africans being seen "clearly in relationship with ourselves and other selves in the universe". This echoes the point about re-centring Africa in the curriculum, and ensuring that the curriculum speaks to, and from, the African context. Ngugi (1981: 87) calls this "a quest for relevance". This relevance can only be established if African universities succeed in decolonising the mind. Kaya and Seleti (2013: 33) concur in stating that a decolonised curriculum must reject the "utilisation of [a] dominant Western worldview of knowing and knowledge production as the only way of knowing". At further grassroots level, the need for an Afrocentric pedagogical lens needs to be infused within the process of teacher induction, allowing the skills to be transferred to classroom practice in an effort to speak to the needs of learners inclusively. It is thus critical to examine the ways of knowing and thinking by examining the values instilled during the process of teacher induction as a means to enlarge teaching spaces that mobilise critical dialogue, connectedness, caring and collective agency. These values need to be critically evaluated when considered how Western discourse shapes the ramifications thereof at a practical level and to question how these core values and knowledge systems either synchronise or regress from the Afrocentric worldview (Cherrington, 2017).

It is important to note that decolonisation does not require removing white men and women, both foreign and local, from the curriculum. However, they cannot be seen as the all-knowing and all-important canon upon which human knowledge rests and through which white and Western domination is maintained (Heleta, 2016). Jansen (1998:110-111) further emphasises that:

Content matters, and it matters a great deal when a European-centred curriculum continues to dominate and define what counts as worthwhile knowledge and legitimate authority in South African texts and teaching; it matters very much in the context of the inherited curriculum, informed by apartheid and colonialism, in which only the more readily observable, offensive racism has been skimmed off the top.

This means that the call for decolonisation of the curriculum "is neither an advocacy to be anti-West, nor is it discouragement to learn from the West" and the rest of the world. Rather, it 
is a call to make higher education (HE) "relevant to the material, historical and social realities of the communities in which universities operate" (Letsekha, 2013: 14). They (academics) need to develop graduates and intellectuals who can address the epistemic violence of the past and present and who will go on to rewrite the "histories and humanity [of both South Africa and Africa] so cruelly seized and denied by Europe" (Zeleza, 2009: 116) throughout centuries. Spivak (1994) defines as "epistemic violence" the Eurocentric and Western domination and subjugation of the (former) colonial subjects and misconception of their understanding and perception of the world. This is a result of the "violence of imperialistic epistemic, social and disciplinary inscription" (Heleta, 2016:4). Thus, the involvement of academics in the decolonisation of curriculum requires "self-reflexivity" (Langdon, 2013:385), recognition of privilege, personal change and growth as well as unlearning of the old knowledge designed to subjugate and exploit "the other".

In essence, higher education needs to trouble the traditional notion of what curriculum is in light of the quest for decolonisation. The idea of curriculum is hardly new - but the way one understands and theorises it has altered over the years - and there remains considerable dispute as to its meaning (Van den Akker, 2006). In the same sense, we need to trouble how teachers reflect and act upon the curriculum (as well as their own identities); and thus to inform and equip teachers to be able to speak to the views and traditions of the African child. Francis and le Roux (2011) speak to the importance of teacher induction to respond to issues of social justice, drawing on the complexity of the myriad of identities which shape not only the perspective of the teacher, but also the connectedness of the African child and, in essence, all identities that are located within one classroom.

Many higher education teachers are asked to decolonise the curriculum, yet there is little agreement as to whether teachers are prepared for this task. Subsequently, this paper is an attempt to articulate, through the case study of a university in South Africa, what higher education teachers understand by the terms curriculum, their understanding of how curriculum should be decolonised and the process involved, their critical analysis of writing for a decolonised curriculum and their suggestions to enhance the decolonisation writing process. Furthermore, as argued by le Roux (2014,) it becomes increasingly important during teacher induction to challenge the subjectivities of teachers as to power and privilege, as a means to enhance restorative pedagogies that will cater to all knowledge systems. This is despite the teachers' personal contexts and assumptions about what knowledge should and should not be taught; thus, challenging assumptions of how teachers think about their own practice and accordingly accommodating multiculturalism.

While universities globally have formulated new policies and frameworks pertaining to equality, equity, transformation and change, institutional cultures and epistemological traditions have not changed considerably. The policies might be there, but the willingness to implement them is lacking (Department of Education, 2008:41). This is evident by students' recent call for decolonisation of the curriculum. Additionally, the 2008 Report of the Ministerial Committee on Transformation and Social Cohesion and the Elimination of Discrimination in Public Higher Education Institutions reiterated this point: "discrimination, in particular with regard to racism and sexism, is pervasive in our institutions. There is a disjuncture between institutional culture and transformation policies" (McKaiser, 2016:16). This report by the Ministerial Committee in turn placed urgency on many higher education institutions to (re)think how knowledge is constructed and presented; in particular, How do we teach beyond content and numbers? Yet the extent of the preparedness of higher education teachers to respond 
to this call remains unknown. How higher education teachers understand and conceptualise decolonisation of the curriculum is somewhat unclear. This is evident by the lack of research done in this area (HESA, 2014:7). The current research can provide a sturdier analysis of higher education teachers' understanding of decolonisation of the curriculum and contribute towards the emerging discussion on decolonising of curriculum in higher education within the South African context.

The content-cleansing process to rid curriculum of prejudicial content continues to unfold in many higher education institutions. However, there is still a dearth of knowledge as to the ideological subtexts of curriculum. As lecturers in Curriculum Studies, we became conscious through informal conversations of the difficulties many lecturers face in terms of writing a curriculum that responds to decolonisation. Getting to grips with the lecturers' experiences of writing for a decolonised curriculum at the Faculty of Education and seeking to arrive at a deeper understanding of the intricacies surrounding these curriculum issues was in itself a strong motivation for us to embark on this investigation. It is accordingly that this research article speaks to the following three research questions:

Research Question 1: How has a writing programme for honours curriculum reform transformed lecturer perceptions about their own practice during a process of decolonising the curriculum?

Research Question 2: What influence does power and personal knowledge have during the process of decolonising the curriculum at honours level?

Research Questions 3: What challenges do lecturers encounter during the process of decolonising the curriculum?

These questions will be answered through firstly exploring the theoretical framework that underpins the study, the work of Michel Foucault (Foucault, 1980). Thereafter, the methodology will be presented, after which the narratives of the participants will be discussed to better understand the context within which academics decolonise the curriculum.

\section{Problem Statement and Rationale}

We don't want to be treated like symptoms, we want to see ourselves reflected in the curriculum, and we want to share our African experiences and knowledge (UFS student, 2016).

After 21 years of democracy, when it might have been expected that curriculum matters should have been adequately addressed, student protests have ignited debates on, "What does it mean to be at a university in Africa?", with responses mostly being related to the relevance of what is taught (Maserumule, 2015). Student protests fuelled by anger have highlighted that curricula at African universities are not linked to African cultures and realities (Molefe, 2016). Students have argued that most universities still follow the hegemonic "Eurocentric epistemic canon" that "attributes truth only to the Western way of knowledge production" (Mbembe, 2016: 32). Such curricula do not develop students' critical and analytical skills to understand and move the African continent forward. The one-sided and subjective "epistemological truth" reflected in curricula is a "reproduction of epistemological blindness that silences other knowledge's and ways of creating knowledge" (Motta, 2013:97).

In response to the task of decolonising the curriculum, higher education teachers at the Faculty of Education of a South African university embarked on a Bachelor of Education (BEd) 
honours-curriculum writing workshop with the purpose of (re-)thinking ways of knowing, a deconstruction of old epistemologies and an inclusion of culturally responsive knowledge. Higher education teachers at this university engaged collaboratively in a two-day-long writing workshop effectively responding to the "question of the moment", i.e., of the decolonisation of curriculum. This study explored the experiences of eight lecturers at the Faculty of Education who participated in the BEd Honours writing exercise with the purpose of decolonising the curriculum.

\section{Theoretical framework}

The theoretical ideas of Michel Foucault (Foucault, 1980) underpin this study. Foucault theorised about interrelated concepts of regimes of truth, power and knowledge. Particular disciplines have specific knowledge that will dominate and point to what is considered true. Foucault (1980: 131) refers to this as "regimes of truth". These regimes of truth guide how people think, feel and act in relation to the self, others and social practice (MacNaughton, 2003). Regimes of truth are represented through a specific subject knowledge. Yet, "what counts as knowledge" is also an issue of "whose knowledge", since knowledge is always "someone's knowledge" (Englund, Forsberg \& Sundberg, 2012). Therefore, regimes of truth consist of symbols that carry meaning, and a curriculum is the medium of conveying meaning, liberation, reproduction, inclusion and exclusion. Foucault has also used the phrase "the politics of knowledge" and describes processes by which "knowledge functions as a form of power and disseminates the effects of power" (Foucault, 1980:69).

Through contextualising the study, we as researchers and academics questioned who holds the power when a specific curriculum is interpreted or transformed and how academics and stakeholders specifically consider how their knowledge is imbedded in certain restrictions, bias and power systems that fail to realise the ideals of a decolonised curriculum.

\section{According to Foucault (1980:369):}

Power/knowledge is located within the "deep" regimes of discourse/practice. It is knowledge that permits statements [about expectations and practices for children and programmes] to emerge and be legitimated as truth. It is produced by power and in turn produces power.

To Foucault (1980), knowledge and power cannot be separated. The type of knowledge produced influences the individual's behaviour and has a controlling effect, such that knowledge is inseparable from power. Knowledge is neither universal nor is it a given, unmediated representation of the world; rather, it is a fallible product under social, cultural and historical constraints. If higher education is to re-centre itself, academics and other staff must be invited to engage with the powerful knowledges they bring in. An understanding of Foucault's regimes of truth, power and knowledge will provide a deeper understanding of lecturers' understanding of writing for a decolonised curriculum. An understanding of how regimes of truth and power and knowledge are embedded in the curriculum could contribute towards the emerging discussion on decolonising of curriculum through a critical lens. Higher education teachers need to "understand that curriculum is a powerful signifying system... so that they may have increased agency in this critical task of decolonisation" (Foucault, 1980:250). This is done through investigating how academics, working in close relation with teacher induction programmes, and specifically the honours programme in Education, mediate 
and navigate power relations, knowledge bias and background influences when shaping their curriculum, ultimately translating into practice on the part of teachers at grassroots level.

\section{Methodology}

\subsection{Research design and paradigm}

The interpretive paradigm was selected to underpin the assumptions of this study. In this paradigm, the aim of educational research is to understand the meaning, in this case, behind higher education teachers' experiences, which is part of the social and cultural context in which they occur (Kim, 2003). Symbolically, the role of the researcher is to understand, explain and demystify social reality through multiple interpretations that vary, whereby results are created and not found (Mack, 2010). Studies in this field are distinctive and cannot be generalised, typical of such case study research (Christiansen, Bertram \& Land, 2010). This suggests that the interpretive paradigm together with the case study research style is the most suitable approach because it deals with personal experiences (similar to the aim of this study).

As a form of qualitative research, a case study has been chosen as the research style for conducting this study. Case studies are implemented when researchers intend to support their argument by a thorough analysis of a person, a group of persons, an organisation or a specific project (Christiansen et al., 2010). From an interpretive perspective, case studies aim towards a deeper understanding of how participants relate and interact with each other in a contextspecific situation and the meaning that arises from the phenomena under study (Maree, 2007).

\subsection{Data collection and ethical approval}

Interviews represent a systematic way of talking and listening to people in order to generate data used for research purposes (Cohen \& Crabtree, 2006). The study at hand employed a semi-structured method of interviewing eight lecturers individually over a thirty-minute session. Used effectively, individual semi-structured interviews inculcate an atmosphere for participants to feel free in expressing their views in their own terms that can provide reliable, comparable qualitative data (for in-depth description).

Ethical approval was obtained at institutional level on part of the Ethics Committee for the Faculty of Education of the respective university where the study was conducted. Furthermore, gatekeeper consent on the part of the Dean of Education was obtained, while all participants were fully informed and briefed about the study, with consent provided to be interviewed.

\subsection{Participants}

Teddlie (2007) describes a sample as the representative selection of people, places or things from which data are gathered. The specific context in which this study took place was a higher education institution in South Africa. The purposive sampling method was selected, which is frequently used in qualitative studies. Purposive sampling involves selecting individuals or institutions to answer the research questions of a study (Teddlie, 2007). The participants in this study included the eight most accessible lecturers (convenience sampling) who were part of the BEd honours writing exercise for the semi-structured one-on-one interviews and who formed core stakeholders in shaping and teaching honours-level courses at the Faculty of Education of the selected university. 


\title{
Analysis of results
}

Validity and reliability are core concepts during researching either quantitative or qualitative designed studies, and specific consideration is given to the importance thereof in relation to this qualitative based paper. According to Holloway and Wheelers (1996: 162), "validity is the extent to which any researcher's tool measures what is supposed to measure and reliability is the extent to which the instrument, when used more than once, will produce the same results or answers in the research". For this qualitative case study, these two concepts are replaced by the concept trustworthiness, which is used in qualitative studies, where measurement is not important because qualitative studies deal with description. Since the case study style of research was implemented in this study, the aim was to describe and not to measure (Christiansen et al., 2010). In describing trustworthiness in qualitative studies, the concepts of credibility, neutrality, confirmability, dependability, applicability and transferability supplant issues of reliability and validity in evaluating the quality of the research (Golafshani, 2003). Therefore, to enhance trustworthiness in this study, two researchers interviewed the eight lecturers and recorded (with tape recorders) the interviews to be transcribed. Data from the two researchers were compared for triangulation purposes.

\section{Results and discussion}

The introduction of the results and discussion section is best informed through a direct verbatim extract of one of the participants, participant 7 , whose narrative embodies the paving of the discussion forward in relation to decolonising the curriculum:

\begin{abstract}
Decolonisation refers to the dismantling of colonial systems and content within the curriculum that were established during the period of time when nations-maintained dominion over dependent territories. Decolonising the university curriculum could happen by tapping into different indigenous knowledge systems, thus expanding the knowledge base that students can access. One major problem of Europe is that content of Europe is over-represented in theory, knowledge and education presented at local universities. I believe that the way forward is move towards practical actions that need to be taken. This include the thoughts and writings of African academics and to draw from African experiences (knowing, doing and being) (Participant 7).
\end{abstract}

Through the analysis of results and the coding process, two dominant themes emerged, namely, "Liberation and dismantlement of Eurocentric knowledge power" and "Collaboration amongst stakeholders in decolonising the curriculum". Of note, however, is that various subthemes also emerged, amongst others, "The longitudinal process of decolonising curriculum" and "Ambiguity of policy and curriculum in the South African process". In relation to the theoretical framework, however, we postulated that these themes reconstruct and organise segmented knowledge akin to Western discourse through empowering the views of the researchers. As such, the discussion of results is informed mainly through the voices of the participants within a uniform non-segmented discussion, organically conveying meaning and as such removing systemic power and colonial dissemination of results on part of the researchers. We in turn needed to question our own manner of knowing and doing, and, in essence, the "being" of the discussion itself. This process mirrors that of not only the thinking that pre-service teachers should critically embody, but speaks to the practice for teachers who will need to rethink and frame to teach within an Afrocentric context.

Participant 1: We forgot... We forgot a lot of things to say. As young as you are, you are a leader in your own making. That's what you're supposed to know. 
From the onset of interviewing, the concept of collaboration and self-empowerment became a prominent part in what methods are of importance in deconstructing power and relocating curricula within a decolonised context. It is important to note that these values are core to indigenous knowledge systems of the African child. While emphasis on part of the researchers was primarily on higher education, the participants relocated the narratives back to grassroots school-based level. The idea of Ubuntu enveloped these narratives, and, as proposed by Swanson (2007), Ubuntu provides the pivotal departure point of togetherness and human rights, especially in relation to schooling contexts, as a means to transcend past injustices and societal disharmony. Participant 1 continued the narrative of forgotten knowledge by relocating power back to the self as well as shared accountability:

To me, decolonising a curriculum means embracing yourself, your culture and other people's capabilities. It means understanding, at a young age, that being a better person doesn't mean looking down at other people. Because when the young ones were groomed, trying to make them better leaders for tomorrow, something was missing there. We forgot about Ubuntu.

This forgotten knowledge may be attributed to the Western mindset of individualistic imperialism dominating human capital movements in educational motives, while collectivist cultures are continuously growing and aiming toward the transcendence of individualistic needs toward leaders with collectivist-based skillsets (Triandis, 2018). Participant 2 emphasised the role of self-liberation, and rejected Eurocentric knowledge systems completely:

Do we mean that we have to ignore other stuff from European countries, from America, from different parts of the world; does it mean that? I think it does mean that, by decolonisation; it seems as if people are thinking of being ... of being liberated themselves. My, you know, decolonisation is about being emancipated cognitively.

The narrative, however, strongly situates and emphasises the systemic nature of nonindigenous knowledge rooting curricula and in a sense restraining emancipation. It is, however, of note that the narrative aligns with Ngugi (1981), who postulated that relevance can only be found if African universities succeed in decolonising the mind. As the interview continued, however, and after reflecting on their own knowledge and construction of decolonising the curriculum, the participant revaluated their previous statement and reconstructed their narrative to draw more freely on the limitations, as per their own perception, of current theoretical lenses underlying current indigenous knowledge systems:

I must say that we, we do have indigenous theorists, uh, but they are not, uh, adequate, to me, so we need to supplement what we have here with what is already existing from other parts of the world.

One of the prominent conversations we had prior to commencing the study pertains to how a lecturer can decolonise a curriculum within the balance of Eurocentric and Afrocentric knowledge systems. We further discussed the difficulty of drawing on indigenous knowledge systems as a primary point of departure. Participants 4 and 5 mirror this discussion, and again draw on the restraints of looking through a primary Afrocentric lens in shaping and constructing the curriculum, this being central to their narratives when asked what decolonising the curriculum entails:

Participant 4: When we're decolonising the curriculum, it mustn't be addressing something that is outside the South African context; it must be within, so to show an understanding, 
and it must address all the issues that are there in that particular country; you cannot learn about England, we're not in England, basically.

Participant 5: You remember, most of the curriculum, especially in African states, it's from overseas. It was brought in during the period of colonisation by those big countries. Now, the content is actually, or most of the time, is a mirror of what is happening in those countries. So with the effect that now it sort of ignores the indigenous knowledge that the country has. And, as a result, the people are saying that it's time that now the indigenous knowledge that the country has also to be recognised to be part of the curriculum that has to be learnt. Hence, decolonisation.

The notion of collaboration and reconciliation of knowledge was articulated by Participant 3 , who acknowledged the limitations of a solely African-centred curriculum and advocated the importance of global collaboration as a means to establish rapport in common ground between teaching and what content should be taught:

It is about $30 \%$ of international knowledge and $70 \%$ of local knowledges. And if you don't adhere to that ratio of $30 / 70 \%$ and then you can't tell that the indigenous knowledge is part of the content. You have to select the readers and the content to reflect on the local context.

Participant 6 also advocated this collaboration of incorporating Western discourse and African-centred knowledge, yet simultaneously acknowledged that this is due to the academic motive of engaging with international conferences and academic collaborators as a primary means of enrichment, neglecting African stakeholders. Participant 6 echoed this through the following narrative:

I think it is a balance between the two ... They all start with a rush on the right [Western] side of the continent and I think through all this we just have to keep a balance, and maybe the yardstick would be which aspect from whichever side will serve the purpose the best without neglecting the other side, because I think for many years academics saw, uhm, let's say, enrichment as going overseas. No one wanted to go up in Africa and go and share and go and learn there.

It becomes noteworthy that the dominant discourse of the initial part of the interviews located the power of what content must be taught in the hands of the lecturers; however, further conversations revealed the importance of participating at various levels. Considering the induction process of teacher education and that all participants were lecturing honourslevel students at the time of the study, the information on the part of these students became of critical value to shaping curriculum. It is furthermore important to reflect again on the narrative of Participant 1 of "forgotten knowledge", and that as for higher education teachers, the continuous recycling of knowledge implies power and sustains systemic oppression, in other words, lecturers provide a specific knowledge base to students, which in turn becomes cornerstone to the knowledge taught within the classroom. Thus, establishing this direct link with educators becomes a critical component in establishing rapport with student educators to be prepared to enter schooling environments with the heightened cultural intelligence that serves the needs of the multicultural contexts of South African schools (Swanepoel, Beyers \& De Wet, 2017). The following narratives are examples of this collaborative stance to shaping a decolonised curriculum:

Participant 5: Like, l'm saying, it involves the involvement of stakeholders, be it from the student side, the private sector as well as the different faculties in an institution, so that at 
least we are not accused of one faculty being advanced or effecting changes while some are still stagnant.

Participant 4: We need, uh, workshops, because you cannot work alone; you have to consult the stakeholders, all those who are involved. That includes the community, politicians, students, parents, all sorts of people, all the stakeholders that are expected to contribute. They have to involve the teachers, because they are the one who are implementing the curriculum.

Participant 1: Embrace other people's culture and take everyone as an asset. Make use of all the capabilities. Hmmm. Be cognisant that you can never decolonise curriculum as an individual who will teach others hence, and then begin to change, to transform curriculum.

The narrative extracts above reflect the basis of how the lecturers conceptualised and located their understanding of decolonising the curriculum. As noted the commencement of the section, there is ambiguity about what content should be included. It was though seen as a process, as opposed to a once-off reimplementation of merely reconfiguring current content, as reflected through the following narratives:

Participant 1: How do we begin to decolonise curriculum? Because it's not going to happen in a minute. I believe it's going to take some time, but we need to make sure that the first thing is collaborating: sitting down and talking about it.

Participant 4: Uhm, basically, curriculum is too broad. We, we, you cannot define it in a short way. It is just a set of, uh, a set of ... what can I say? Uuuh, philosophies that can be combined together to create meaning, basically; for curriculum, because it's too broad.

Of note is that through this process that we, the two researchers, had a chance to further reflect on our own ideas and perceptions of decolonisation. Coming from two different universities and having undergone different induction programmes, we realised the manner in which we do not just hold our individual background knowledge and bias, but also a different knowledge-structure, based on our separate experiences as students and ultimately lecturers. Coming together and having undergone this study, we can speak to the importance of collaboration, Ubuntu and sharing knowledge as a means to broaden how we structure our curriculum. Thus not seeing curriculum transformation as being within a silo, but as a collaborative approach wherein individual differences are embraced and translated into the manner in which we create and design curriculums, as well as how we approach teaching this curriculum at practical level.

\section{Final reflection and demarcations of the study}

After reflection on part of the researchers, it became indicative that the participants' narratives contain finer nuances of what and how curriculum is perceived and produced. Participants alternated between using "the curriculum" and "a curriculum" or "curriculum". Aligned with the basis of the study this reflects the distinctive conceptions that there is a fluid and non-unison formation of what curriculum is, while other participants may perceive curriculum more as a set framework. This is reiterated through Participant 1 who articulates that "curriculum" is formal and informal, and that lecturers themselves may represent the current primary stakeholders:

It could be lessons acquired by students in schools or in universities imparted by educators or lecturers. It could be knowledge articulated in schools. It could be knowledge that has not been articulated but, because of the environment, the student has something, I mean 
they've acquired something subconsciously without having anyone who say: "This is what you're supposed to do". It could be knowledge that came from certain courses. It could be things that were not taught formally. As I'm saying, in a university a student might be able to acquire something from the environment without anyone saying a word. That what "curriculum" is to me.

We agree that the manner in which curriculum is shaped and implemented for new teachers need to challenge existing norms of what knowledge is being taught and the manner in which it is conveyed. Ultimately, as lecturers of honours level education students, we need to relocate our own perceptions of knowledge and construction of content to incorporate the views and grassroots level experiences of teachers within the system. This study focussed on lecturers, and further research will be valuable, from a systemic perspective, to gain stronger insight as to how indigenous knowledge systems in schools are currently implemented, challenged, troubled and ultimately adapted to fit the current content set out to be taught on part of all various stakeholders and to the benefit of the learners. It is only through critical examination and questioning that teachers will embody the skills to speak to the needs of the African child without the distorted lenses of Western influence; and in turn critically engage with the need to develop multicultural skills and competencies to cater to the African context.

\section{References}

Akoojee, S. \& Nkomo, M. 2007. Access and quality in South African higher education: The twin challenges of transformation. South African Journal of Higher Education, 21(3), 385-399.

Cherrington, A. 2017. Positioning a practice of hope in South African teacher education programmes. Educational Research for Social Change, 6(1), 72-86. https://doi. org/10.17159/2221-4070/2017/v6i1a6

Christiansen, I., Bertram, C. \& Land, S. 2010. Understanding research. Pietermaritzburg: University of KwaZulu-Natal.

Cohen, D. \& Crabtree, B. 2006. Qualitative research guidelines project. Available at http:// www.qualres.org/HomeSemi-3629.html [Accessed 22 March 2013]

Department of Education. 2008. Report of the ministerial committee on transformation and social cohesion and the elimination of discrimination in public higher education institutions. Pretoria: Department of Education.

Englund, T., Forsberg, E. \& Sundberg, D. 2012. Teaching as an offer of discursive meaning. New York: Peter Lang.

Foucault, M. 1980. Power/knowledge. New York: Pantheon.

Francis, D. \& Le Roux, A. 2011. Teaching for social justice education: The intersection between identity, critical agency, and social justice education. South African Journal of Education, 31(3), 299-311. https://doi.org/10.15700/saje.v31n3a533

Garuba, H. 2015. What is an African curriculum? Available at http://mg.co.za/article/2015-0417-what-is-an-african-curriculum/ [Accessed 15 June 2017]

Golafshani, N. 2003. Understanding reliability and validity in qualitative research. The Qualitative Report, 8(4), 597-607. 
Heleta, S. 2016. Decolonisation of higher education: Dismantling epistemic violence and Eurocentrism in South Africa. Transformation in Higher Education, 1(1), 1-8. https://doi. org/10.4102/the.v111.9

Higher Education South Africa (HESA). 2014. South African higher education in the $20^{\text {th }}$ year of democracy: Context, achievements and key challenges. Presentation to the Portfolio Committee on Higher Education and Training, 5 March, Cape Town, South Africa.

Holloway, I. \& Wheeler, S. 199). Qualitative research for nurses. Oxford: Blackwell Science Publishers.

Jansen, J.D. 1998. But our natives are different! Race, knowledge and power in the academy. Social Dynamics, 24(2), 106-116. https://doi.org/10.1080/02533959808458653

Kaya, H.O. \& Seleti, Y.N. 2013. African indigenous knowledge systems and relevance of higher education in South Africa. The International Education Journal: Comparative Perspectives, 12(1), 30-44.

Kim, S. 2003. Research paradigms in organisational learning and performance: Competing modes of inquiry. Information Technology, Learning and Performance Journal, 21(1), 9-19.

Langdon, J. 2013. Decolonising development studies: Reflections on critical pedagogies in action. Canadian Journal of Development Studies, 34(3), 384-399. https://doi.org/10.1080/0 2255189.2013.825205

Le Grange, L. 2016. Decolonising the university curriculum. South African Journal of Higher Education, 30(2), 1-12.

Le Roux, A. 2014. We were not part of apartheid: Rationalisations used by four white preservice teachers to make sense of race and their own racial identities. South African Journal of Education, 34(2), article 11. https://doi.org/10.15700/201412071137

Letsekha, T. 2013. Revisiting the debate on the Africanisation of higher education: An appeal for a conceptual shift. The Independent Journal of Teaching and Learning, 8, 5-18.

Mack, L. 2010. The philosophical underpinnings of educational research. Polyglossia, 19(1), 5-9. MacNaughton, G. 2003. Shaping early childhood: Learners, curriculum contexts. Berkshire: Open University Press.

Maree, K. (Ed). 2007. First steps in research. Pretoria: Van Schaik.

Maserumule, M.H. 2015. Why Africa's professors are afraid of colonial education being dismantled. The Conversation. Available at https://theconversation.com/why-africas-professorsare-afraid-of-colonial-education-being-dismantled-50930 [Accessed 25 November 2017].

Mbembe, A. 2016. Decolonising the university: New directions. Arts \& Humanities in Higher Education, 15(1), 29-45. https://doi.org/10.1177/1474022215618513

McKaiser, E. 2016. Epistemic injustices: The dark side of academic freedom, 2016 DCS Oosthuizen Academic Freedom Memorial Lecture. Available at http://www.iol.co.za/news/ epistemic-injustices-the-dark-side-of-academic-freedom-2029747 [Accessed 17 June 2017].

Mgqwashu, E. 2016. Universities can't decolonise the curriculum without defining it first. The Conversation. Available at https://theconversation.com/universities-cant-decolonise-thecurriculum without-defining-it-first-63948 [Accessed 14 February 2018] 
Molefe, T.O. 2016. Oppression must fall: South Africa's revolution in theory. World Policy Journal, 33(1), 30-37. https://doi.org/10.1215/07402775-3545858

Motta, S.C. 2013. Teaching global and social justice as transgressive spaces of possibility. Antipode, 45(1), 80-100. https://doi.org/10.1111/j.1467-8330.2012.00995.x

Ngugi, W.T.O. 1981. Decolonising the mind: The politics of language in African literature. Nairobi: East African Educational Publishers Ltd.

Spivak, G.C. 1994. Can the subaltern speak? In P. Williams \& L. Chrisman (Eds.). Colonial discourse and post-colonial theory: A reader, pp. 66-111. New York: Harvester/Wheatsheaf.

Swanepoel, E.H., Beyers, C. \& De Wet, L. 2017. Exploring judgement and internal bias of Life Orientation teachers in sexuality teaching. TD: The Journal for Transdisciplinary Research in Southern Africa, 13(1), 1-12.

Swanson, D.M. 2007. Ubuntu: An African contribution to (re) search for/with a "humble togetherness". Journal of Contemporary Issues in Education, 2(2), 53-67.

Teddlie, C. 2007. Mixed methods sampling: A typology with examples. Journal of Mixed Methods Research, 1(1), 77-100. https://doi.org/10.1177/1558689806292430

The Higher Education Summit. 2015. Transforming higher education for a transformed South Africa in a 21st century world: A call to action. International Convention Centre in Durban, KwaZulu-Natal.

Theron, L.C. \& Theron, A.M. 2014. Education services and resilience processes: Resilient Black South African students' experiences. Children and Youth Services Review, 47, 297306. https://doi.org/10.1016/j.childyouth.2014.10.003

Triandis, H.C. 2018. Individualism and collectivism. London/New York: Routledge. https://doi. org/10.4324/9780429499845

Van den Akker, J. 2006. Curriculum development re-invented. In J. Letschert (Ed.). Curriculum development re-invented, pp. 16-30. Enschede: SLO.

Zeleza, P.T. 2009. African studies and universities since independence: The challenges of epistemic and institutional decolonization. Transition, 101, 110-135. https://doi.org/10.2979/ trs.2009.-.101.110 